Área Abierta. Revista de comunicación

audiovisual y publicitaria

ISSN: 2530-7592 / ISSNe: 1578-8393

\title{
Un recorrido pedagógico por algunos programas de divulgación científica de la televisión en España
}

\author{
Víctor Grande-López ${ }^{1}$
}

Recibido: 20 de marzo de 2020 / Aceptado: 4 de junio de 2020

Resumen. La televisión como medio de comunicación se ha acercado a la ciencia con la intención de aportar información rigurosa y relevante. El objetivo de este estudio es analizar algunos programas de divulgación científica de la televisión en España para que puedan emplearse como material audiovisual. Se efectúa una selección de programas de televisión que sirven como catálogo audiovisual para que puedan ser utilizados por los docentes. Desde una metodología cualitativa se desarrolla un análisis del conjunto de signos transmisores de mensajes emitidos a través del discurso audiovisual, se elabora una descripción y se procede a su clasificación en función de la tipología de programa científico según Lehmkuhl et al. (2012). Dicha propuesta está dirigida a la Educación Secundaria Obligatoria que comprende edades entre los doce y dieciséis años. Y finalmente, a través de la alfabetización científica, el alumnado se familiariza con el lenguaje científico, obtiene valores morales y adquiere un mayor interés por descubrir nuevos conocimientos.

Palabras clave: Ciencia; Televisión; Adolescentes; Alfabetización científica; Pensamiento científico; Comunicación Audiovisual

\section{[en] A Pedagogical Tour of Some Programs of Scientific Dissemination of Television in Spain}

\begin{abstract}
Television as a means of communication has approached science with the intention of providing rigorous and relevant information. The objective of this study is to analyze some scientific dissemination programs on television in Spain so that they can be used as audiovisual material. A selection is made of television programs that serve as an audiovisual catalog in order for them to be used by teachers. From a qualitative methodology, an analysis of the set of signs transmitted through the audiovisual discourse is undertaken, a description is prepared and its classification proceeds according to the type of scientific program according to Lehmkuhl et al. (2012). This proposal is aimed at Compulsory Secondary Education, which includes ages between twelve and sixteen years old. And finally, through scientific literacy, students become familiar with scientific language, obtain moral values and acquire a greater interest in discovering new knowledge.
\end{abstract}

Keywords: Science; Television; Teenagers; Scientific Literacy; Scientific thinking; Audiovisual Communication

Sumario. 1. Introducción. 2. Objetivos y metodología. 3. Selección y análisis de los programas. 4. Resultados y discusión. 5. Conclusiones. 6. Bibliografía. 
Cómo citar. Grande-López, Víctor (2020). Un recorrido pedagógico por algunos programas de divulgación científica de la televisión en España. Área Abierta. Revista de comunicación audiovisual y publicitaria 20 (2), 177-190, http://dx.doi.org/10.5209/arab.68426

\section{Introducción}

La ciencia es esencial para nuestra prosperidad, nuestra seguridad, nuestra salud, nuestro medio ambiente y nuestra calidad de vida, más de lo que ha sido en cualquier tiempo pasado. (Barack Obama, 2009, en Grosso Mesa, 2017: 54)

Tal como indica Solbes (1999: 3), "Se enseña ciencias porque la burguesía revolucionaria pensaba que podía contribuir a la destrucción de mitos y fanatismos que obstaculizaban una mayor racionalidad en la sociedad humana". Estaba presente desde un valor útil al servicio del Estado, pero con el triunfo de la burguesía conservadora las ciencias se establecieron al servicio de la industria (Martínez-Bonafé, 1985). Seguidamente, su finalidad fue vinculada al conocimiento y la formación dirigiéndose a la comunidad educativa. Las sociedades avanzadas fueron estableciendo una necesidad por la cual los ciudadanos pudieran tener voz propia para poder opinar, participar y votar sobre temas científicos (Hodson 1994).

Los docentes detectan en el alumnado una lejanía en relación al interés por la ciencia y destacan la necesidad de que se adquieran conocimientos útiles para comprender el entorno científico y técnico (Boyre y Tiberghien, 1989), ya que dichas enseñanzas permiten explorar, descodificar y valorar el entorno en el que una persona se encuentra.

Se percibe en la educación secundaria cierto desaliento, debido a una falta de razonamiento abstracto y dificultad en ver su aplicación científica al ámbito cotidiano. Esto conlleva a que el alumnado tenga que dedicarles a las asignaturas con contenido en ciencia un mayor tiempo, voluntad y esfuerzo. Valdés González (2018) destaca que las niñas y los niños nacen con cualidades de científicos, ya que desde pequeños son grandes observadores del mundo: su curiosidad y su capacidad instintiva para el aprendizaje empírico, les llevan hacia habilidades exploratorias en busca de intentar entender mejor el entorno que les rodea. Por lo general, los contenidos sobre ciencia les apasionan, tienen curiosidad por el universo, los dinosaurios, el fondo submarino, etc. En cambio, cuando se enfrentan a las materias sobre ciencia en el aula les empiezan a parecer aburridas y se comienza a percibir una progresión en desmotivación que se va acentuando al llegar a la educación secundaria (Gopnik, 2012).

Una de las mayores carencias que encuentran los docentes en el aula es la falta de capacidad de reflexión. Rico (1993) resalta que para conseguir la autonomía de niñas y niños es imprescindible dicha capacidad ya que favorece a que entiendan lo indefinido y, por ello, es necesario educar desde el entusiasmo como base para que quieran seguir aprendiendo a lo largo de sus vidas.

Estudios realizados por Ibáñez Ibáñez, Romero López y Jiménez Tejada (2019) sobre los libros de texto de Educación Secundaria y su relación con la ciencia in- 
dican que en los libros de Biología y Geología o en los libros de Física y Química existe una patente falta de reflexión sobre qué es la ciencia y cómo se construye. Las autoras resaltan que los textos olvidan destacar el componente creativo e imaginativo, limitan en casi todos ellos dar un ejemplo y el número de actividades crítico-argumentativas es bajo. También respecto a las actividades subrayan que: "se echa en falta más presencia de las que requieren argumentación y pensamiento crítico, ambos necesarios para formar a ciudadanos responsables" (Ibáñez Ibáñez, Romero López y Jiménez Tejada, 2019: 63). Y es que, aunque: “el ser humano es curioso por naturaleza a veces necesita que alguien le ponga delante no solo las respuestas sino también las preguntas adecuadas" (Caballero, 2017: 1).

Tal como exponen Cano-Orón, Portalés Oliva y Llorca-Abad (2017) según el último informe sobre percepción social de la ciencia (FECYT, 2015), la televisión en España es el principal medio al que, con mayor frecuencia, están expuestos los ciudadanos para informarse sobre ciencia y tecnología. San Sebastian Ikutza (2015) destaca que la televisión educativa si se utiliza bien puede ser muy útil en la adquisición de conocimientos, no solo como medio de comunicación sino como valor pedagógico. Los programas de televisión de divulgación científica integrados en la enseñanza educativa favorecen el aprendizaje observacional debido a su comunicación multisensorial y lleva al alumnado a pensar más mediante aprendizajes superiores divergentes (Grande-López, 2019).

San Sebastian Ikutza (2015:11) indica que: "un programa de televisión puede explicar de forma atrayente conceptos que a priori resultan pocos seductores". Y es que transmitir información científica y tecnológica desde un lenguaje accesible descodificado logra que la comunidad educativa adquiera conocimientos que suelen encontrarse exclusivamente reservados a los profesionales de la investigación (Calvo Hernando, 2002). El no contar con dichas enseñanzas empobrece a una sociedad que cada vez más depende de ella, ya que no hay que olvidar que la ciencia contribuye a crear sociedades más inteligentes. La pequeña pantalla en ese sentido ha sido un medio que desde sus inicios ha divulgado multitud de conocimientos sobre temas de interés científico, "una televisión que bien utilizada puede ser una perfecta herramienta educativa" (Ferrerós, 2005:12) y tal como hace referencia Brian Cox: "Cuanta más ciencia haya en la televisión mejor nos irá como sociedad" (Calvo Hernando, 1997:181).

\section{Objetivos y metodología}

El objetivo de este estudio es analizar algunos programas de divulgación científica de la televisión en España para que puedan servir como material audiovisual a los profesionales de la docencia. Siendo un recurso motivador desde un vehículo lúdico para que el alumnado adquiera no solo una mayor comprensión en conceptos de ámbito científico, sino curiosidad y entusiasmo como estímulos positivos en sus aprendizajes. Desde el medio audiovisual el alumnado adquiere mejor algunos contenidos que puedan resultar más difíciles de trasmitir al docente desde los recursos tradicionales (San Sebastian Ikutza, 2015).

Dicha propuesta de ámbito educomunicativa se realiza a través de una revisión bibliográfica de autoras y autores que han abordado sus estudios desde la ciencia, televisión y educación. Se efectúa una selección de programas de televisión mediante 
visionados alojados en la red de internet, en la hemeroteca de Radio Televisión Española y en el registro documental de Canal Sur, obteniéndose un total de treinta y ocho programas que sirven como catálogo audiovisual para que pueda ser utilizado por los docentes. Desde una metodología cualitativa, se desarrolla un análisis del conjunto de signos transmisores de mensajes emitidos a través del discurso audiovisual, se elabora una descripción de cada uno de los programas seleccionados y se procede a su clasificación en función de la tipología de programa científico desarrollada por Lehmkuhl et al. (2012: 1011-1012) que los clasifica en variantes para establecer un análisis más preciso.

Y finalmente, dicha propuesta está dirigida a la Educación Secundaria Obligatoria que comprende edades entre los doce y dieciséis años. El motivo se debe a que tal como establecen en sus estudios Vázquez y Manassero (2008) detectan que existe un punto de inflexión notable a la edad de los doce años en el que se pierde interés por la ciencia, siendo de vital importancia despertar la atracción ante dichos aprendizajes. Las imágenes en movimiento educan la atención del alumnado, siendo tan necesario actualmente en el mundo educativo debido a que cada vez más se detecta en las aulas un trastorno de déficit de atención (Grande-López, 2018).

\section{Selección y análisis de los programas}

A continuación, se presentan treinta y ocho programas en cuya selección se ha tenido en cuenta la calidad de los contenidos científicos y tecnológicos, su forma de comunicarlos y los valores que aportan. Tras dicha selección, se lleva a su posterior análisis con el objetivo de extraer resultados que puedan ayudar a reforzar enseñanzas desde un vehículo de entretenimiento.

\begin{tabular}{|c|l|}
\hline $\begin{array}{c}\text { Programas de televisión de divulgación } \\
\text { científica en España }\end{array}$ & Año/s de emisión \\
\hline Del observatorio a su receptor & 1956 \\
\hline Visado para el futuro & 1963 \\
\hline Las fronteras de la ciencia & 1966 \\
\hline Misterios al descubierto & 1966 \\
\hline Amigos del espacio & 1968 \\
\hline Fauna & 1968 \\
\hline Aventura & $1970-1971$ \\
\hline Planeta Azul & $1970-1974$ \\
\hline El hombre y la Tierra & $1973-1980$ \\
\hline Más vale prevenir & $1979-1987$ \\
\hline La bola de cristal & $1984-1988$ \\
\hline Metrópolis & 1985 - actualidad \\
\hline Documentos TV & 1986 - actualidad \\
\hline Érase una vez... la vida & 1987 \\
\hline
\end{tabular}




\begin{tabular}{|c|c|}
\hline Hablemos de sexo & 1990 \\
\hline La aventura del saber & 1992-actualidad \\
\hline Érase una vez... los inventores & 1994 \\
\hline Más por menos & 1996 \\
\hline Redes & 1996-2007 \\
\hline El escarabajo verde & 1997 \\
\hline Saber vivir & $1997-2009$ \\
\hline Salud al día & 2000 - actualidad \\
\hline Dos rombos & 2004 \\
\hline Tecnópolis & 2005 \\
\hline El hormiguero & 2006 - actualidad \\
\hline Redes 2.0 . & $2008-2014$ \\
\hline Espai Terra (Espacio Tierra) & 2009-2017 \\
\hline ConCiencia & 2012 \\
\hline Tres 14 & 2014 \\
\hline$L a b 24$ & 2014 \\
\hline Yo, mono & 2015 \\
\hline El cazador de cerebros & 2016 \\
\hline Ciencianosa & 2016 \\
\hline Desafia tu mente & 2016 \\
\hline ¿Qué me pasa doctor? & 2016 \\
\hline This is art & $2017-2018$ \\
\hline Órbita Laika & 2019 \\
\hline Tesis & 2019 \\
\hline
\end{tabular}

Tabla 1. [Fuente: elaboración propia]

Seguidamente se adjunta una tabla con las comunicadoras y comunicadores de divulgación científica extraídos del estudio junto a los tipos de ciencias que se presentan en los programas:

\begin{tabular}{|c|l|}
\hline Comunicadores/as & \multicolumn{1}{|c|}{ Ciencias } \\
\hline Mariano Medina & Meteorología \\
\hline Luis Miravitlles & Física, Geología, Astronomía \\
\hline Félix Rodríguez de la Fuente & Ecología, Zoología \\
\hline Ramón Sánchez-Ocaña & Medicina, Nutrición \\
\hline Elena Ochoa & Sexología \\
\hline Mario de la Mano & Ecología \\
\hline Eduard Punset & Biología, Neurociencia \\
\hline Roberto Sánchez & Medicina, Nutrición \\
\hline
\end{tabular}




\begin{tabular}{|c|l|}
\hline Lorena Berdún & Sexología, Psicología \\
\hline Jorge Marrón & Química, Física \\
\hline Tomás Molina I Bosch & Ciencias ambientales \\
\hline Luis Quevedo & Astronomía, Nutrición... \\
\hline Pere Buhigas & Nutrición, Oceanografía... \\
\hline Pablo Herreros & Antropología \\
\hline Pere Estupinya & Medicina, Tecnología... \\
\hline María Solar & Física, Tecnología \\
\hline Jorge Mira & Física, Química \\
\hline Bartolomé Beltrán & Medicina \\
\hline Ramón Gener & Sociología \\
\hline
\end{tabular}

Tabla 2. Comunicadores/as y los tipos de ciencias que han tratado los programas del estudio. [Fuente: elaboración propia]

Los programas de divulgación científica aportan un gran valor cognitivo: fomentan la curiosidad en el alumnado por medio de los diferentes fenómenos -meteorológicos, biológicos, geológicos, tecnológicos, etc. -, despiertan un mayor grado de atención y consiguen promover un mayor interés por la ciencia a través del aula.

Grosso Mesa (2017) destaca que la televisión en España desde sus inicios ha trasmitido contenidos de divulgación científica mediante divulgadores como el meteorólogo Mariano Medina, que fue el conductor del espacio Del observatorio a su receptor (1956) y realizó la sección de El Tiempo en el programa informativo Telediario, donde con una pizarra y tiza o una cartulina y rotulador, describía a modo ilustrativo las predicciones meteorológicas. Al principio, no aparecía en la pequeña pantalla a excepción de su brazo, por el que se hizo popular. En esos principios, Macías (2015) hace referencia a Luis Miravitlles como uno de los primeros divulgadores de ámbito científico en la televisión española: fue profesor de Bioquímica y Geología, y miembro de la Comisión Especial de Selenología de la NASA. Entre sus programas en TVE se encuentran: Visado para el futuro (1963), Las fronteras de la ciencia (1966) o Misterios al descubierto (1966) sobre cómo funciona un microscopio, cohetes espaciales o fenómenos atmosféricos mediante preguntas como: ¿Por qué existen precipitaciones?

Otro programa de TVE basado en cuestiones de astronáutica y presentado por J. A. Rosa y Ana María Paso fue Amigos del espacio (1968). Era un momento donde en 1963 según el Libro blanco de la Educación (1969) había en España un 17,1\% de personas analfabetas, siendo prácticamente el mismo porcentaje que en el año 1940. Miravitlles repetía en sus programas que: "Saber es útil, soñar es necesario e imaginar es imprescindible" (Grosso Mesa, 2017: 98).

Recuerdo estar en casa y oír a mi padre: "Coged todas las formas esféricas que encontréis, pelotas de todos los tamaños...". En una manta colocaba una bola en el borde y por mucho que estiráramos la manta, ésta siempre iba hacia el centro. De esa forma, explicaba Miravitlles la ley de la gravedad en uno de sus programas (Macías, 2015: 4).

La televisión es un potente agente socializador en el que sus imágenes en movimiento hacen trabajar posteriormente a la memoria. Para la asignatura Geografía e 
Historia de primero de la E.S.O. dichos espacios audiovisuales refuerzan enseñanzas en la iniciación a la Astronomía, fenómenos atmosféricos, viajes espaciales, efectos fisiológicos de la estancia en el espacio, instrumentación astronómica o zonas bioclimáticas. Propuesta que lleva al alumnado a una reflexión y a cuestionarse el porqué de los problemas medioambientales, como la contaminación plástica que está dañando a los océanos, el rápido derretimiento de los glaciares o el aumento que se está produciendo de incendios. Por dichos motivos, es necesario crear una mayor concienciación ambiental y social en el aula, ya que tal como apunta Torres (2013: 1): "Tomar agua nos da vida, pero tomar conciencia nos dará agua".

En divulgación científica medioambiental Félix Rodríguez de la Fuente, de entre muchos de sus logros, a finales de los años sesenta contribuye desde la televisión a que se proteja y se salven especies que se encuentran en peligro de extinción. En los años setenta, Rodríguez de la Fuente y su equipo de televisión pasaron cuatro años siguiendo a una manada de lobos para recoger un material audiovisual de apenas treinta minutos. Algo que hoy en día cobra un mayor valor debido a una sociedad que quiere resultados rápidos y sin apenas tiempos de espera. De sus trabajos para TVE se encuentran: Fauna (1968), Aventura (1970-1971), Planeta Azul (1970-1974) y El hombre y la Tierra (1973-1980).

Su divulgación medioambiental logró cambiar en España las conciencias con respecto a la conservación y protección del medio ambiente y surgieron los primeros movimientos ecologistas. Hoy en día, el medio ambiente va directamente unido a la salud del ser humano, desde la contaminación del aire, mala calidad del agua, exposición de sustancias químicas en alimentos, contaminación acústica, etc. (Grosso Mesa, 2017).

Seguidamente, en los años ochenta, década donde la televisión española llevaba a quien se encontraba delante de la pantalla a pensar más como un ciudadano y no como un cliente, Lolo Rico creó uno de los programas más influyentes de TVE titulado La Bola de Cristal (1984-1988). Rico apostó por una televisión no solo de entretenimiento sino de conocimiento, acercando la cultura de una forma divertida. Aportó a un público infantil y juvenil multitud de términos tecnológicos. Entre ellos, el orticón, que es un tubo analizador de imagen basado en el iconoscopio y antecesor de las cámaras de televisión. Saticón, plumbicón y vidicón, haciendo referencia a los modelos de tubos que llevaban las cámaras de video. El ánodo y el cátodo, como tipos de electrodos que se encuentran en celdas electroquímicas siendo las más conocidas las pilas. O términos relacionados con la capacidad eléctrica como son el culombio (C) y el faradio (F).

Una de las marionetas que aparecían en el programa llamada Bruja Avería repetía constantemente frases como: “¡Por Orticón, Saticón y Vidicón, nadie sabe cómo detener la infracción!” siendo inevitables en el programa las relaciones entre ciencia, tecnología y educación, viniendo de guionistas como Carlo Frabetti, matemático y divulgador científico o el filósofo Santiago Alba (Rico, 2003).

San Sebastian Ikutza (2015) muestra que la televisión desde la divulgación incita a querer saber más, enseña a disfrutar aprendiendo: descubrir que el saber permite entender las cosas y el entendimiento lleva al disfrute. Marga Iñiguez, la asesora pedagógica del programa La Bola de Cristal (1984-1988), destaca su valor indicando que el programa es un puente entre la fantasía y la realidad y reinventar otras realidades para una mayor apertura mental (...) (Rico, 2003:115).

En divulgación científica y médica asesorados por el Ministerio de Sanidad, TVE emitió Más vale prevenir (1979-1987) un espacio conducido por el periodista Ra- 
món Sánchez-Ocaña. En esos años, los contenidos sobre ciencia, salud, cultura y tecnología fueron pasando hacia un discreto lugar en el segundo canal de televisión denominado inicialmente UHF, que años después fue llamado TVE-2 y actualmente La 2. En esos inicios, se destacaban programas que siguen en emisión como Metrópolis (1985) un espacio sobre cultura y arte contemporáneo y Documentos TV (1986) programa basado en documentales y reportajes de diferentes temáticas.

Palomo (2012) hace referencia a una serie de animación titulada Érase una vez... la vida -Il était une fois ... la vie, France 3, 1987-que inspiró a que algunos profesionales de la medicina eligieran dicha carrera siendo adolescentes, activando un pensamiento creativo y creando vocación científica. Su creador Albert Barillé tuvo que documentarse exhaustivamente sobre el cuerpo humano: se leyó más de cien libros, contó con el periodista científico Alexander Dorozynski y con Joel de Rosnay quien fuera presidente del CNRS -Centro Nacional para la Investigación Científica-. Años más tarde, Barillé creó la serie de animación Erase una vez... los inventores -Il était une fois... les Découvreurs, France 3, 1994- basada en las invenciones de los más importantes inventores de la historia. De las muchas virtudes que tienen los dibujos animados como recurso didáctico en el aula destacan sus valores educativos y la empatía visual que generan.

En sexología como ciencia para mejorar la calidad de la vida sexual de las personas se hace referencia al programa Hablemos de sexo (1990) conducido por la sexóloga Elena Ochoa y emitido por TVE. Contaba con diferentes asesores médicos y se hablaba por primera vez en España de la salud sexual en televisión. Redes (1996-2007) fue un programa de divulgación científica presentado por Eduard Punset y emitido por la 2. Entre sus contenidos destacaban temas relacionados con la biología, la astronomía o la neurociencia. En 2007, el programa pasó a denominarse Redes 2.0 (2008-2014) siendo pionero en utilizar un plató virtual, animación 3d y videoconferencias (Grosso Mesa, 2017).

En la divulgación de las matemáticas Más por menos (1996) era un espacio emitido dentro del programa de la 2 La aventura del saber (1992) espacio que lleva veintisiete años de emisión. Algunos de los contenidos matemáticos que se podían aprender desde el programa eran el número áureo, el mundo de las espirales, la primera suma matemática, las leyes del azar, el número e, etc. Un espacio divulgativo que aporta conocimientos a una de las asignaturas que suele crear mayores dificultades en los entornos educativos como son las matemáticas; de ahí la importancia de unir la divulgación de las matemáticas con la didáctica para despertar un mayor interés.

Sobre la ecología como rama de la biología se indica el programa El escarabajo verde (1997) presentado por el periodista Mario de la Mano y emitido por el canal de televisión La 2. En medicina y psicología se hace referencia a Saber vivir (1997) un programa cuyo objetivo era promover mejoras en la calidad de vida de las personas. Y desde Canal Sur Televisión se destacan dos programas, Salud al día (2000) un espacio de información y servicio público que tiene como objetivo mejorar en el espectador sus conocimientos sobre salud y Tecnópolis (2005) programa divulgativo en I+D+I (Investigación, Desarrollo e Innovación), ambos programas conducidos por el periodista Roberto Sánchez. Cuando se educa en salud se favorecen hábitos saludables en el alumnado y se adquiere alfabetización sanitaria: es esencial que los estudiantes adquieran hábitos saludables y sobre todo enseñarles a pensar en la salud. Sobre divulgación sexual Dos rombos (2004) fue un programa de TVE presen- 
tado por la psicóloga y sexóloga Lorena Berdún donde se mostraba la importancia de la educación sexual: en la adquisición de conocimientos, en la aceptación de la persona, en el respeto, divulgar para que la sexualidad no se convierta en un tabú, ya que debido a las enfermedades contagiosas a las que están expuestos los adolescentes, más vale informar en el aula que curar.

El hormiguero (2006) es un programa presentado por Pablo Motos que incluye una sección de ciencia elaborada por un laboratorio científico de doce personas entre las que se encuentran desde físicos, un experto en robótica, ingenieros electrónicos y de telecomunicaciones. Una sección conducida actualmente por Jorge Marrón basada en experimentos acerca de los siguientes temas entre otros: el efecto de Bernoulli, fluido newtoniano, estados metaestables del agua, unión magnética, esculturas con ferrofluidos, electricidad estática, efecto del agua ingrávida, etc. Todas las semanas preparan para el programa unas cien ideas de las que salen luego en pantalla unas cinco, seis o siete (Sanz Ezquerro, 2017).

La información a través de las imágenes que proyecta la televisión favorece en el alumnado el grado de atención y curiosidad respecto a los libros de texto, estimulando el valor emocional y desarrollando procesos de reflexión. En TV3, principal canal de Televisión de Cataluña, se emitió el programa Espai Terra-Espacio Tierra, 2009-2017- sobre medio ambiente y cultura. Un espacio que fue presentado por Tomás Molina i Bosch, jefe de meteorología de la Televisión de Cataluña. ConCiencia (2012) desde Andalucía Televisión es un programa que informa, entretiene y educa sobre la ciencia. Tres 14 (2014), presentado por el biotecnólogo Luis Quevedo, trata sobre diferentes disciplinas científicas a través de entrevistas y reportajes y Lab 24 (2014), presentado por el periodista e ingeniero técnico de telecomunicaciones Pere Buhigas, siendo ambos programas emitidos por el canal de televisión La 2 y el canal 24 Horas, trasladan a los espectadores conceptos de ámbito científico desde un lenguaje sencillo. Sobre antropología el programa Yo, mono (2015) fue emitido por La 2 y presentado por el sociólogo, antropólogo y divulgador científico Pablo Herreros, pionero en la divulgación primatológica en España: un programa que analizaba los comportamientos humanos basándose en el comportamiento animal.

El cazador de cerebros (2016) es un programa presentado por el bioquímico Pere Estupinya que realiza un viaje por todo el mundo acercando a los espectadores los conocimientos de ilustres investigadores. Desde la Televisión de Galicia (TVG) se destaca el programa Ciencianosa (2016) conducido por la periodista María Solar y el físico y divulgador científico Jorge Mira, siendo un espacio que promueve de una forma didáctica y motivadora la labor científica de la ciencia gallega (Martínez Rolán, 2007).

De experimentos y juegos que ponen a prueba la capacidad de la mente humana se encuentra el programa Desafia tu mente (2016) que fue emitido por La 1 y se basa en el programa Brain Games de National Geographic. Sobre medicina se encuentra el espacio ¿Qué me pasa doctor? (2016) emitido por el canal La Sexta y presentado por el Doctor Bartolomé Beltrán, un programa de actualidad donde se resuelven dudas a través de expertos sobre la salud. En arte, This is art (2017-2018) es un programa emitido por \#0 de Movistar+ y La 2 presentado por Ramón Gener, en el que se muestra el valor del arte a través de las emociones, ejemplos como el por qué una simple fotografía puede conmover tanto a una persona y a otra no. Sobre la importancia de canalizar el rigor de la ciencia a través del sentido del humor Órbita Laika (2019) es un espacio emitido por La 2 donde intervienen científicos y personalidades 
de cualquier ámbito profesional que pretenden hacer divertida la ciencia y unir el intelecto con la emoción de la alegría o la sorpresa. Basado en monólogos, citas de personajes ilustres y secciones que promueven el valor de la ciencia, el nombre del programa tiene su origen en la perra rusa Laika, que fue el primer ser vivo terrestre en orbitar la Tierra el 3 de noviembre de 1957, la cual murió horas después del lanzamiento. Para finalizar este recorrido por algunos de los programas de divulgación científica, se destaca el programa Tesis (2019) que se emite en el canal Andalucía Televisión y que presenta algunos de los trabajos académicos de investigación que realizan las universidades andaluzas.

\section{Resultados y discusión}

Se refleja en los estudios que asignaturas de la E.S.O. donde se desarrollan contenidos sobre ciencia no suelen generar un cierto interés, lo que genera desmotivación en el alumnado. Entre los factores que los docentes encuentran se destacan: una falta de razonamiento abstracto, dificultad para ver la ciencia como algo importante en el día a día, ausencia de capacidad de reflexión y sentido crítico.

Ibáñez Ibáñez, et al. (2019) hace referencia a que existen varias investigaciones que sugieren un mejor aprendizaje en la enseñanza de la naturaleza de la ciencia desde un enfoque explícito y reflexivo (Acevedo, 2009; Khishfe y Abd-El-Khalick, 2002; Koskal et al., 2013; Lederman y Lederman, 2014) y sobre la necesidad de utilizar la televisión educativa como un vehículo de comunicación de gran alcance, Sánchez Carrero (2005) indica que acerca enseñanzas, debido a que transmite normas, valores y conceptos.

A través del análisis de los programas de divulgación científica presentados en el estudio se obtiene que:

- La información que se transmite de una manera visual y simplificada favorece al docente sus enseñanzas en el aula.

- Desde un recurso audiovisual se genera un aprendizaje observacional que activa el grado de atención y la curiosidad.

- Mediante un lenguaje multisensorial y desde un canal lúdico se consigue que el alumnado no sienta que está siendo educado, interiorizando mejor los contenidos.

- A través de la información que se proyecta el docente puede relacionarla con el entorno del alumnado, simplificando mejor los espacios.

- Visionar experimentos científicos genera un factor sorpresa en el que se interiorizan emociones agradables y al pasar por el cerebro emocional se retiene mejor la información.

- Desde el entramado audiovisual se origina una estética atrayente, promoviendo un aprendizaje más atractivo y estimulador.

En los resultados obtenidos en función a la tipología sobre programas científicos de Lehmkuhl et al. (2012: 1011-1012) que los clasifica en variantes para establecer un análisis más eficiente se indica: 
1. Programas de popularización, que suelen tratar un tema en profundidad e insertan los resultados científicos en un contexto más amplio, con el objetivo de atraer al espectador-Del observatorio a su receptor, Visado para el futuro, Las fronteras de la ciencia, Misterios al descubierto, Amigos del espacio, Redes, Redes 2.0., Lab 24 y Yo, mono-. Dichos contenidos podrían reforzar actividades en asignaturas de la E.S.O como: Geografía e historia, Ciencias de la Naturaleza, Educación Plástica, Visual y Audiovisual, Física y Química y Comunicación Audiovisual.

2. Programas de edutainment, entretener educando a partir de ideas y procesos científicos -La bola de cristal, Metrópolis, Documentos TV, Érase una vez... la vida, La aventura del saber, Érase una vez... los inventores, Más por menos, Tecnópolis, El hormiguero, ConCiencia, Tres 14, El cazador de cerebros, Ciencianosa, Desafía tu mente, This is art, Órbita Laika, Tesis-. Contenido dirigido para actividades en asignaturas de la E.S.O como: Matemáticas, Educación Plástica, Visual y Audiovisual, Biología y Geología, Física y Química y Comunicación Audiovisual.

3. Programas de consejos de salud-Más vale prevenir, Hablemos de sexo, Saber vivir, Salud al día, Dos rombos y ¿Qué me pasa doctor? - podrían reforzar contenidos mediante actividades en asignaturas de la E.S.O como: Biología y Geología, Educación Física, Comunicación Audiovisual.

4. Programas de defensa o sobre el medio ambiente en los que se une experiencia científica con activismo político - Fauna, Aventura, Planeta Azul, El hombre y la Tierra, El escarabajo verde y Espai Terra (Espacio Tierra- desarrollándose actividades en asignaturas de la E.S.O como: Ciencias de la Naturaleza, Biología y Geología y Comunicación Audiovisual.

Los objetivos de las enseñanzas en ciencia en sus inicios tal como establece Solbes (1999) eran los del conocimiento, utilidad y la importancia de educar en valores científicos. De los programas recogidos en el estudio de una manera transversal, no solo generan conocimientos en ciencia y tecnología, sino que también aportan valores emocionales -creatividad, sensibilidad, optimismo, etc.-y morales -solidaridad, compromiso, generosidad, tolerancia, respeto o responsabilidad-.

Con respecto a promover el interés por la ciencia en el aula, cuando se proyectan imágenes desde un contenido educativo no cuentan solo con un significado, debido a que se suman a las correspondientes explicaciones del docente y el posterior coloquio como aprendizaje dialogado del que el alumnado adquiere un mayor aliciente. Un debate posterior al visionado favorece una mejor retención del contenido, se adquiere mayor información por parte de las aportaciones de compañeros, se obtiene un aprendizaje cooperativo, se fomenta la alfabetización mediática y se genera un pensamiento divergente y crítico.

Sobre los tópicos que existen con respecto a una televisión educativa, García Matilla, (2003: 28) lo desmonta justificando que la televisión es necesaria para educar, que entre sus objetivos se encuentra: "Combatir la desmemoria, compensar la desinformación y dotar de herramientas para reunificar la realidad". Ante una infoxicación y fake news que cada vez transitan más desde el medio internet, se acentúa la necesidad de promover espacios que generen saberes y despierten un sentir crítico para lograr subsanar cualquier tipo de información que llegue desde la pseudociencia. 


\section{Conclusiones}

Antes se dedicaba en el aula un mayor tiempo para aprender a leer -lecto-escriturade forma comprensiva y capacidad interpretativa, pero ahora con las nuevas tecnologías es necesario aprender a saber ver y a leer los códigos y su significado -lecto-audiovisual - ya que se adquiere una mayor capacidad cognitiva, empatía visual y sentido crítico. El aprendizaje que se obtiene a través de un lenguaje multisensorial, sumado a las enseñanzas del docente que complementan el visionado y finalmente su posterior debate por medio de un aprendizaje dialogado, son estrategias en el aula que generan una mayor empatía por el contenido, motivación e indagación, incitando al alumnado a querer aprender más.

Los programas sobre divulgación científica presentados en el estudio aportan un valor práctico que es necesario para la educación secundaria, que se sustenta mayoritariamente de materiales textuales. Cuando se fomenta lo visual se adquiere un mayor grado de atención por el contenido desde un aprendizaje observacional y el alumnado sitúa esos fenómenos científicos proyectados - meteorológicos, biológicos, geológicos, tecnológicos, etc.- a través de las imágenes al entorno más cercano, siendo un factor diferenciador ante los libros de texto. Desde un vehículo de entretenimiento no sienten que están siendo educados y les facilita la interiorización del contenido sobre ciencia en asignaturas de la E.S.O como: matemáticas, geografía e historia, ciencias de la naturaleza, educación plástica, visual y audiovisual, biología y geología, física y química, comunicación audiovisual y educación física.

Se ha demostrado en el estudio que para promover un mayor grado de interés sobre la ciencia es vital su formación de una manera atrayente desde los entornos educativos. Que los jóvenes tomen conciencia de que la ciencia es innovación, transformación, que logra mejorar sus calidades de vida tanto en el ámbito de la salud, como en la alimentación o en el medio ambiente. Existen temas importantes de ámbito científico que los programas de televisión deben desarrollar más para que posteriormente se trabajen en las escuelas: contenidos relacionados con la climatología, como ciencia que estudia el clima y que desde la alfabetización climática logran crear una mayor conciencia ante la actual crisis ecosocial. O la alimentación y sus efectos siendo importante desde el binomio alimentación-salud, para sensibilizar acerca de las consecuencias de una mala praxis, debido al uso excesivo de pesticidas por medio de prácticas poco sostenibles. Cuando se proyecta determinada información en la pantalla se transmiten conocimientos desde el entretenimiento que organizan y fluyen mejor en los pensamientos. Favorecen los estados de ánimo del alumnado, conocen mejor sus responsabilidades, toman una mayor conciencia y eso les lleva a la acción. La televisión, debido a su influencia social y alcance mediático, actúa como agente transformador que el docente debe de aprovechar en el aula, su contenido debido a los códigos verbales y visuales pasa por el cerebro emocional y logra que el alumnado retenga mejor la información.

Se percibe en la revisión bibliográfica gran cantidad de estudios científicos en esta última década que se encuentran relacionados con programas de televisión vinculados al periodismo del corazón o a los programas cuyos contenidos son calificados con el neologismo de telebasura, llegándose a la conclusión de la necesidad de mostrar también estudios sobre programas de televisión que generen un valor positivo desde la ciencia y la tecnología. Como futuras líneas de investigación se puede establecer estudios sobre otras temáticas de programas de televisión como puede ser 
la gastronomía para llevarla a los entornos educativos: la cocina televisada de una forma educativa sirve como recurso para que el docente pueda llevarlo a las enseñanzas de las escuelas de Hostelería y Turismo o Ciclos formativos tanto de Cocina y Gastronomía como de Restauración (servicios en restaurantes, bar o cafetería).

Para finalizar, la pequeña pantalla que nació en 1956 en España se ha hecho grande, pero a pesar de llegar a la edad adulta debe saber que tiene que estar siempre en continuo aprendizaje, de ahí la importancia de divertir, distraer, pero también informar, concienciar y formar; una televisión más inteligente Smart TV que mejora técnicamente pero que no puede olvidar su capacidad creativa, que transite en mayores contenidos desde la ciencia y la tecnología para ofrecer conocimientos científicos en los entornos educativos. En definitiva, una televisión para seguir aprendiendo de ella y que los docentes puedan aprovechar sus cualidades como recursos didácticos, desde el intelecto y lo lúdico, la empatía cognitiva y el valor emocional.

\section{Bibliografía}

Boyer, R. y Tiberghien, A. (1989): "Las finalidades de la enseñanza de la Física y la Química, vistas por los profesores y alumnos franceses", en Enseñanza de las Ciencias, número 3, 213-223.

Caballero, L. (2017). "Jóvenes, divertidos y frikis: los científicos españoles que conquistan YouTube", en El Confidencial. Recuperado de: https://bit.ly/2P6wSYf (Fecha de acceso: 07/10/2019).

Calvo Hernando, M. (1997). Manual de periodismo cientifico. Barcelona: Bosch.

Calvo Hernando, M. (2002). "La divulgación científica y tecnológica. Del periódico a la sociedad de la información", en Sociedad Estatal España Nuevo Milenio, número 2, 245260.

Cano-Orón, L., Portalés Oliva, M. y Llorca-Abad, G. (2017). "La divulgación en la televisión pública: el caso de RTVE en 2016", en adComunica. Revista Científica de Estrategias, Tendencias e Innovación en Comunicación, núm. 14, 201-228.

Ferreros, M.L (2005). Enséñale a ver la tele. Barcelona: Planeta, S.A.

García Matilla, A. (2003). Una televisión para la educación. La utopía posible. Barcelona: Gedisa.

Gopnik, A. (2012). "Scientific Thinking in Young Children: Theoretical Advances, Empirical Research, and Policy Implications", en Science, núm. 337.

Grande-López, V. (2018). "Ver mundos diferentes estimula la imaginación", en revista científica de educación y comunicación Hachetetepé, núm. 17, 71-82.

Grande-López, V. (2019). "Una mayor empatía al VIH/sida a través de la educomunicación" en Revista Española de Comunicación en Salud, vol. 10, núm. 1, 102-108.

Grosso Mesa, J. (2017). Ciencia en televisión: las estrategias divulgativas del programa Redes 2.0 de Eduard Punset (TVE, 2008-2013). Tesis doctoral. Universidad de Granada.

Hodson, D. (1994). "Seeking Directions for Change. The Personalisation and Politisation of Science Educaction", en Curriculum Studies, núm. 1, 71-98.

Ibáñez Ibáñez, M. M., Romero López, M. del C. y Jiménez Tejada, M. del P. (2019). “¿Qué ciencia se presenta en los libros de texto de Educación Secundaria?”, en Enseñanza de las ciencias, núm. 37, 49-71.

Lehmkuhl, M., Karamanidou, C., Mörä, T., Petkova, K., y Trench, B. (2012). "Scheduling Science on Television: A Comparative Analysis of the Representations of Science in 11 
European Countries", en Public Understanding of Science, SAGE Publications, núm. 21, 1002-1018.

Macías, A. (2015). "Luis Miravitlles, el primer divulgador científico de TVE". Carta de ajuste. en Otra tele es posible. Blog. Recuperado de https://bit.ly/2uArHZz (Fecha de acceso: 12/10/2019).

Martínez Bonafé, A. (1985). Ensenyament, burgesia i liberalisme. Valencia. Edicions Alfons el Magnànim

Palomo, M. (2012). "Érase una vez la vida... 25 años después", en Dixit comunicación cientifica. Recuperado de: https://bit.ly/384p9R5 (Fecha de acceso: 02/11/2019).

Rico, L. (1993). TV fábrica de mentiras. Madrid: Espasa Calpe, S.A.

Rico, L. (2003). El libro de La bola de cristal. Barcelona: Plaza \& Janes.

San Sebastian Ikutza, I. (2015). La importancia de una televisión educativa. Trabajo Fin de Grado, Grado en Educación Infantil, Facultad de Educación, Universidad Internacional de la Rioja.

Sánchez Carrero, J. (2005). “Al rescate de una televisión para la educación”, en Comunicación, núm. 3, 291-296.

Sanz Ezquerro, D. (2017). “Dentro del laboratorio de los científicos de El Hormiguero", en Periódico El mundo. Recuperado de: https://bit.ly/3a8tQL3 (Fecha de acceso: 05/09/2019).

Solbes, J. (1999). "Los valores en la enseñanza de las ciencias", en Revista Alambique, núm. $22,1-7$.

Torres, D. (2013). “Tomar agua nos da vida, pero tomar conciencia nos dará agua”. No solo frases. Blog. Recuperado de https://bit.ly/2w7BLtw (Fecha de acceso: 25/09/2019).

Valdés González, H. (2018). “¿Cómo despertar vocaciones científicas en los niños?”, en Cuaderno de cultura cientifica. Recuperado de: https://bit.ly/3cyKRQD (Fecha de acceso: 09/12/2019).

Vázquez, Á. y Manassero, M. A. (2008). "El declive de las actitudes hacia la ciencia de los estudiantes: un indicador inquietante para la educación científica”, en Revista Eureka sobre Enseñanza y Divulgación de las Ciencias, vol. 3, núm. 5, 274-292. 